\title{
EDITORIAL
}

\section{Dairy protein, calcium and body weight - the need for a mechanism}

International Journal of Obesity (2005) 29, 388-390. doi:10.1038/sj.ijo.0802878

Published online 21 December 2004

The possibility that increased levels of dietary calcium can reduce body weight or exaggerate weight loss is attracting an increasing amount of attention. NHANES data, cross-sectional and longitudinal studies have shown an inverse relationship between calcium intake and body weight in men, women and children. ${ }^{1-4}$ Other studies find either no association $^{5}$ or that the relation is valid only for obese individuals. ${ }^{6}$ Intervention studies have demonstrated that increasing the calcium intake of African men from 400 to $10000 \mathrm{mg} /$ day for a year caused a $4 \mathrm{~kg}$ reduction in body fat ${ }^{1}$ and that increasing calcium intake increased weight loss in obese subjects on a calorie-reduced diet. ${ }^{7}$ The loss of fat was greatest and more was from abdominal fat if calcium was given with a dairy product. $\mathrm{Zemel}^{8}$ also reported that isocaloric substitution of three dairy servings per day into the diet of obese African-American adults for 6 months resulted in a $5.6 \%$ reduction in body fat mass. Davies et al ${ }^{9}$ analyzed data from osteoporosis trials and found a significant negative correlation between body mass index and calcium intake expressed as calcium: protein ratio, accounting for approximately $3 \%$ of the variation in individual body weight and representing a weight difference of about $0.038 \mathrm{~kg} / \mathrm{y}$ per $100 \mathrm{mg}$ increase in calcium intake. In contrast, Shapes et al ${ }^{10}$ found only a nonsignificant trend for increased weight loss in women supplemented with $1000 \mathrm{mg} \mathrm{Ca} /$ day during a 6-month weight loss trial and Bowen et al ${ }^{11}$ found no difference in weight loss in obese subjects fed an energyreduced diet containing high levels of diary protein and calcium compared with subjects fed a diet of mixed protein and low calcium content. Animal studies also have produced conflicting results. Shi et $a l^{12}$ found that mice expressing agouti protein in white fat lost more weight during food restriction on a high calcium than a low calcium diet and that the loss was exaggerated if some of the calcium came from nonfat dry milk rather than calcium salts. We reported that high levels of dietary calcium caused a small inhibition of weight gain in ad libitum fed rats ${ }^{13}$ whereas Zhang and Tordoff ${ }^{14}$ found no effect of dietary calcium on weight gain or adiposity of ad libitum fed mice.

This issue of International Journal of Obesity contains the latest in a series of papers by Zemel et al describing a beneficial effect of increasing dietary calcium and dairy protein on weight loss in obese subjects following a caloriereduced diet for 12 weeks. Although this study provides additional evidence for calcium and dairy protein playing a role in determining body weight and adiposity, there is no attempt to identify the mechanistic basis of the response. The results are impressive, showing a 22\% increase in weight loss and a $66 \%$ increase in body fat loss in the calcium and dairy-supplemented subjects compared with their controls. Interestingly, almost all of the extra fat (1.4 of the extra $1.7 \mathrm{~kg}$ ) was lost from the trunk and the dairy-supplemented subjects lost less lean tissue than controls (1.35 vs $1.97 \mathrm{~kg}$ in controls). The calcium and dairy-supplemented group consumed three servings of yogurt per day and had a total calcium intake of about $1100 \mathrm{mg} /$ day $(600 \mathrm{mg}$ from the yogurt), compared with an intake of only $500 \mathrm{mg}$ in control subjects. The yogurts provided between 15 and $18 \mathrm{~g}$ of protein ( $\sim 28 \%$ of protein intake) and 300-330 kcal per day ( $\sim 23 \%$ of energy intake) (http://www.generalmills.com/ corporate/brands/product.aspx?catID $=55 \#)$.

Control subjects consumed three $10 \mathrm{kcal}$ servings of gelatin dessert. As the two groups reported dietary intakes with identical proportions of energy from protein, fat and carbohydrate, it has to be assumed that the controls were obtaining their protein from low-calcium foods that also had a lower fat content than those that made up the nonyogurt portion of the diet of the dairy group.

At a time when obesity in both adults and children has reached alarming levels in the United States, ${ }^{15}$ it is important to identify any dietary change that is useful in preventing or ameliorating weight gain. Therefore, the concept of a beneficial effect of calcium and of low-fat dairy products on body weight is very attractive: not only would there be a benefit in terms of body weight but there also is the potential of increasing consumption of high-quality protein and of calcium in an adult population that has a daily calcium intake below the RDA. ${ }^{16}$ For many in the scientific community, however, it is difficult to embrace the efficacy of dietary calcium and dairy protein without a good understanding of the mechanisms responsible for the loss of body fat. Although it may be argued that it is enough to demonstrate an effect of the diet, elucidation of the mechanisms and identification of the critical components that deliver a 
benefit would facilitate development of appropriate and specific dietary recommendations. For example, in the context of calcium and weight loss, it is reported that weight loss is greater if calcium is derived from dairy products rather than a mineral supplement. ${ }^{7}$ The question remains whether the calcium has to be consumed at the same time as dairy protein or has to be part of the dairy matrix, that is, can a person eat one yogurt and a calcium supplement or do they have to eat three servings of yogurt? (The Yoplait Light fruit yogurts used in the study reported here are supplemented with tricalcium phosphate; therefore, a portion of the extra calcium was in mineral form.) Secondly, the greatest benefit has been observed with weight-loss diets including low-fat dairy products, but it is not clear that the same benefit would be derived from full fat diary products or in people who are not limiting calorie intake.

The mechanism of action of calcium and/or dairy protein in promoting loss of body fat has not been investigated in human trials and would require large, tightly controlled studies to elucidate as only small changes in daily energy intake are required to produce the incremental loss of fat. The extra $1680 \mathrm{~g}$ of fat lost by the dairy-supplemented group in the study reported here would require an energy deficit of $180 \mathrm{kcal} /$ day beyond that experienced by the control group, which is within the standard error of reported daily energy intakes. Although only small changes in efficiency of energy utilization are involved, a number of different mechanisms have been proposed to account for the change. One contributing factor is that dietary calcium increases soap formation in the gastrointestinal tract, making fat unavailable for absorption and reducing calorie intake. ${ }^{17-18}$ Parikh and Yanovski ${ }^{19}$ calculated that an extra $2000 \mathrm{mg}$ calcium/day in a $2500 \mathrm{kcal} /$ day diet would bind enough lipid to account for a body weight loss of about $0.5 \mathrm{~kg}$ per year, which is equivalent to the weight difference that has been attributed to dietary calcium intake in the analysis by Davies et al ${ }^{9}$ Similarly, increased fecal excretion of lipid accounted for all of the difference in body fat content of rats fed a high-calcium diet. ${ }^{13}$ The impact of increased calcium intake during food restriction has not been evaluated but, theoretically, it could produce a proportionally greater energy deficit in low-calorie, low-fat diets.

More elaborate mechanisms for the change in body fat based on shifts in cellular metabolism have been proposed by Zemel's group based on cell culture and mouse studies. ${ }^{8}$ They hypothesize that an increased dietary intake of calcium downregulates parathyroid hormone and $1,25(\mathrm{OH})_{2}$ vitamin $\mathrm{D}$ (calcitrol). The reduction in calcitrol increases calcium uptake into adipocytes, which then inhibits fatty acid synthesis, stimulates lipolysis and increases expression of uncoupling protein 2 (UCP2). The increased UCP2 expression and fall in calcitrol concentration has recently been associated with increased adipocyte apoptosis attributed to a collapse of mitochondrial membrane potential and inhibition of ATP production. ${ }^{20}$ Current opinion on the function of UCP2 in vivo is that it prevents cellular oxidative damage, which would be protective against apoptosis, and may transport fatty acids but is unlikely to mediate proton leak across the mitochondrial membrane. ${ }^{21}$ Although each of the proposed relationships has been tested independently, their relevance to the in vivo human situation has not been examined in a consistent manner. It is essential that this aspect of the response be investigated, not only to provide support for the hypothesis but also to demonstrate that the moderate changes in hormone levels and cellular calcium that would be anticipated in human studies have a significant impact on lipid mobilization in a condition of energy deficit, when lipolysis is already stimulated. Melanson et $a^{22}$ reported that whole-body fatty acid oxidation correlated with 24-h calcium intake, but not with 4-day (habitual) calcium intake. The increased oxidation would be appropriate if calcium stimulates lipolysis and increases fatty acid oxidation, but an association with habitual calcium intake would be expected if this was part of the metabolic basis of weight loss induced by high calcium diets. If a decrease in circulating calcitrol is central to the mechanisms of weight loss then the source of dietary calcium would not be important and the influence of dairy protein would be independent of calcium. In addition, the impact might be expected to be greater in individuals in energy balance because those on a restricted diet would already be in a catabolic state. None of these proposed mechanisms would account for a greater rate of fat loss from visceral fat, as was reported for the dairy-supplemented subjects compared with controls. Zemel hypothesizes that a fall in calcitrol will result in a lower rate of adipocyte conversion of cortisone to cortisol in adipose tissue by the enzyme $11, \beta$-hydroxysteroid dehydrogenase 1 (11, $\beta$ HSD-1). Cortisol inhibits preadipocyte proliferation but promotes differentiation. The importance of adipose-derived cortisol in obesity and the development of the metabolic syndrome is currently unresolved ${ }^{23,24}$ and the impact of changes in circulating concentrations of calcitrol remains to be determined.

Less information is available on the mechanism by which dairy protein might deliver an added benefit in terms of promoting loss of body fat and protecting lean tissue. Dairy protein contains high concentrations of branched chain amino acids (BCC) and Layman ${ }^{25}$ has suggested that the role of these amino acids in supporting gluconeogenesis, synthesis of other amino acids or muscle protein synthesis is proportional to their availability. If consumption increases there will be greater support of muscle protein synthesis. This would be consistent with the observation that weight loss in dairy-supplemented subjects was composed of more fat and less lean tissue than that in controls. In addition, it has been hypothesized ${ }^{8}$ that inhibitors of angiotensin-Iconverting enzyme that are present in whey protein ${ }^{26}$ may inhibit angiotensin-II stimulation of adipocyte lipogenesis. ${ }^{27}$ The importance of these two potential mechanisms in exaggerating weight loss has yet to be evaluated but neither one is obviously dependent upon calcium intake. Therefore, it is important to determine whether the effects of calcium and dairy protein are additive or synergistic. 
In summary, although a number of potential mechanisms have been put forward to explain the effects of increasing dietary calcium and dairy protein intake on weight loss, the importance of any of these in individuals on a high calcium, high diary and reduced energy diet has yet to be demonstrated. The contribution of fecal fat excretion may be significant when only a small change in daily digestible energy intake is required. The relevance of changes in adipose metabolism requires a demonstration that there is a significant inhibition of calcitrol in individuals consuming high calcium, high dairy diets. Identification of the factors that are important in promoting weight loss, and specifically the repartitioning of nutrients to protect lean body mass, is essential for the development of appropriate dietary recommendations. This was stated most clearly by Weaver and Boushey $^{28}$ 'In general, what is necessary to understand the relationship between dairy and calcium intake and body fat are controlled feeding studies to determine quantitatively the magnitude of the relationship and the mechanisms underpinning the phenomenon'.

\section{RBS Harris ${ }^{1}$}

${ }^{1}$ Department of Foods and Nutrition, University of Georgia, Athens, GA 30602, USA

\section{References}

1 Zemel MB, Shi H, Greer B, Dirienzo D, Zemel PC. Regulation of adiposity by dietary calcium. FASEB J 2000; 14: 1132-1138.

2 Carruth BR, Skinner JD. The role of dietary calcium and other nutrients in moderating body fat in preschool children. Int $J$ Obes Relat Metab Disord 2001; 25: 559-566.

3 Lin YC, Lyle RM, McCabe LD, McCabe GP, Weaver CM, Teegarden D. Dairy calcium is related to changes in body composition during a two-year exercise intervention in young women. $J \mathrm{Am}$ Coll Nutr 2000; 19: 754-760.

4 Lovejoy JC, Champagne CM, Smith SR, de Jonge L, Xie H. Ethnic differences in dietary intakes, physical activity, and energy expenditure in middle-aged, premenopausal women: the Healthy Transitions Study. Am J Clin Nutr 2001; 74: 90-95.

5 Phillips SM, Bandini LG, Cyr H, Colclough-Douglas S, Naumova E, Must A. Dairy food consumption and body weight and fatness studied longitudinally over the adolescent period. Int J Obes Relat Metab Disord 2003; 27: 1106-1113.

6 Pereira MA, Jacobs Jr DR, Van Horn L, Slattery ML, Kartashov AI, Ludwig DS. Dairy consumption, obesity, and the insulin resistance syndrome in young adults: the CARDIA Study. JAMA 2002; 287: 2081-2089.

7 Zemel MB, Thompson W, Milstead A, Morris K, Campbell P. Calcium and dairy acceleration of weight and fat loss during energy restriction in obese adults. Obes Res 2004; 12: 582-590.

8 Zemel MB. Role of calcium and dairy products in energy partitioning and weight management. Am J Clin Nutr 2004; 79: 907S-912S.
9 Davies KM, Heaney RP, Recker RR, Lappe JM, Barger-Lux MJ, Rafferty K, Hinders S. Calcium intake and body weight. J Clin Endocrinol Metab 2000; 85: 4635-4638.

10 Shapses SA, Heshka S, Heymsfield SB. Effect of calcium supplementation on weight and fat loss in women. J Clin Endocrinol Metab 2004; 89: 632-637.

11 Bowen J, Noakes M, Clifton PM. A high dairy protein, highcalcium diet minimizes bone turnover in overweight adults during weight loss. J Nutr 2004; 134: 568-573.

12 Shi H, Dirienzo D, Zemel MB. Effects of dietary calcium on adipocyte lipid metabolism and body weight regulation in energy-restricted aP2-agouti transgenic mice. FASEB J 2001; 15: 291-293.

13 Papakonstantinou E, Flatt WP, Huth PJ, Harris RB. High dietary calcium reduces body fat content, digestibility of fat, and serum vitamin D in rats. Obes Res 2003; 11: 387-394.

14 Zhang Q, Tordoff MG. No effect of dietary calcium on body weight of lean and obese mice and rats. Am J Physiol 2004; 286: R669-R677.

15 Hedley AA, Ogden CL, Johnson CL, Carroll MD, Curtin LR, Flegal KM. Prevalence of overweight and obesity among US children, adolescents, and adults, 1999-2002. JAMA 2004; 291: 2847-2850.

16 Looker AC. Interaction of science, consumer practices and policy: calcium and bone health as a case study. J Nutr 2003; 133: 1987S-1991S.

17 Palmquist DL, Conrad HR. High fat rations dairy cows, tallow and hydrolyzed blended fat at two intakes. J Dairy Sci 1980; 63: 391-395.

18 Shahkhalili Y, Murset C, Meirim I, Duruz E, Guinchard S, Cavadini C, Acheson K. Calcium supplementation of chocolate: effect on cocoa butter digestibility and blood lipids in humans. Am J Clin Nutr 2001; 73: 246-252.

19 Parikh SJ, Yanovski JA. Calcium intake and adiposity. Am J Clin Nutr 2003; 77: 281-287.

20 Sun X, Zemel MB. Role of uncoupling protein 2 (UCP2) expression and 1alpha, 25-dihydroxyvitamin D3 in modulating adipocyte apoptosis. FASEB J 2004; 18: 1430-1432.

21 Rousset S, Alves-Guerra MC, Mozo J, Miroux B, Cassard-Doulcier AM, Bouillaud F, Ricquier D. The biology of mitochondrial uncoupling proteins. Diabetes 2004; 53 (Suppl 1): S130-S135.

22 Melanson EL, Sharp TA, Schneider J, Donahoo WT, Grunwald GK, Hill JO. Relation between calcium intake and fat oxidation in adult humans. Int J Obes Relat Metab Disord 2003; 27: 196-203.

23 Westerbacka J, Yki-Jarvinen H, Vehkavaara S, Hakkinen AM, Andrew R, Wake DJ, Seckl JR, Walker BR. Body fat distribution and cortisol metabolism in healthy men: enhanced 5betareductase and lower cortisol/cortisone metabolite ratios in men with fatty liver. J Clin Endocrinol Metab 2003; 88: 4924-4931.

24 Seckl JR, Morton NM, Chapman KE, Walker BR. Glucocorticoids and 11beta-hydroxysteroid dehydrogenase in adipose tissue. Recent Prog Horm Res 2004; 59: 359-393.

25 Layman DK. The role of leucine in weight loss diets and glucose homeostasis. J Nutr 2003; 133: 261S-267S.

26 Vermeirssen V, Van Camp J, Augustijns P, Verstraete W. Angiotensin-I converting enzyme (ACE) inhibitory peptides derived from pea and whey protein. Meded Rijksuniv Gent Fak Landbouwkd Toegep Biol Wet 2002; 67: 27-30.

27 Ailhaud G, Teboul M, Massiera F. Angiotensinogen, adipocyte differentiation and fat mass enlargement. Curr Opin Clin Nutr Metab Care 2002; 5: 385-389.

28 Weaver CM, Boushey CJ. Milk-good for bones, good for reducing childhood obesity? J Am Diet Assoc 2003; 103: 1598-1599. 